\title{
The ethnographic semiotics of a suburban moral panic
}

\author{
Matthew Durington
}

\begin{abstract}
This article describes Worth's notion of ethnographic semiotics as part of an overall strategy employing the anthropology of visual communication in ethnographic research focused on media portrayals of a suburban community during a moral panic over a concentrated number of teenage heroin overdose deaths. While the full-length ethnography details multiple media events surrounding the moral panic, the central place of one piece of print media is described in detail. This article served as a catalyst for the moral panic that occurred within the suburb, facilitated community response, and became a template for further national media coverage in the United States. In addition, the article became an instrumental research tool for elicitation among informants during ethnographic research. The overall study and employment of Worth's ethnographic semiotics serve as a bridge between foundational studies in the anthropology of visual communication and contemporary methodologies employed in media ethnography.
\end{abstract}

Keywords: Ethnographic semiotics, U.S. suburban studies, moral panic, visual anthropology

\section{An ethnographic semiotic}

Before the death of Sol Worth in 1977, he submitted a funding proposal to the Guggenheim Foundation to write a book entitled Fundamentals of visual communication in preparation for an ambitious visual ethnography of an entire community in central Pennsylvania with Jay Ruby. The proposal was published posthumously in the journal that Worth founded entitled Studies in the Anthropology of Visual Communication. This journal served as a foundation for a growing fi eld within anthropology that included Sol Worth, Larry Gross, Dell Hymes, Jay Ruby, Richard Chalfen and others who sought to combine methods from linguistics, media analysis and ethnography to conduct studies of visual communication. The goal was to practise a type of communication and media 
analysis that would be beholden to anthropological practice, thereby answering many of the supposed deficiencies offered by other modes of media study that did not place culture as their primary concern at the time.

The focus of the proposed study by Worth that was not to occur, and the subject of the book that was never written, centered on the practice of ethnographic semiotics. Worth defined the broad ethnographic semiotic approach as 'the study of how actual people interpret a variety of actual visual events' (Worth 1977, 69). This methodology would concentrate on the way in which individuals related to, and were embedded in, multiple media practices in both a generative and a receptive sense. In other words, it would focus on how people acted as cultural producers of visual materials, and on the way in which people interacted with and interpreted visual events in their daily cultural lives. Essentially, how does one make meaning from their visual universe from those visual events that are produced and mediated to them, or, in turn, are generated by them. As Worth states:

The concept of ethnographic semiotics departs from the customary methods of the study of meaning and interpretation practiced by critics, scholars and connoisseurs on "great works," either of "literature" or "art" - essentially the creation of individual interpretations of individual elite artifacts by the elite. The concept and methods I wish to explore seek instead to inform the reader that the process of interpretation itself as practiced by ordinary as well as elite persons and groups upon ordinary as well as "great" works could be a goal for the analysis of our symbolic world (Worth 1977, 69).

The discussion of the ethnographic semiotic was embedded in Worth's overall project that focused on the application of linguistics and anthropological practice to visual media. While this overall project had its shortcomings, different elements of the approach provided a theoretical framework for the ethnographic analysis of social media events. These elements can be found in four separate parts of Worth's original book proposal. The first part sought to propose a 'theory of interpretive strategies for both "conscious" and "unconscious" articulation and interpretation' (Worth 1977, 69). Essentially, it proposed a theory of visual communication to understand how individuals produce varied media and the means by which people interpret these products. In the second part, Worth proposed analyzing the conception of art and style in a variety of contexts to show how agreed upon definitions of both are impossible due to logical and, most importantly, relative sociocultural reasons (Worth 1977, 69). Third, and perhaps most important to the extension of Worth's methodology, is a focus on how meaning is generated and applied to visual events by individuals. And, lastly, the most ambitious component of the study sought to synthesize methods from semiotics, perception, sociolinguistics, content analysis, communication research, psychoanalysis and ethnographic methods including '...fieldwork, participant observation and the use of visual materials as elicitation techniques as well as research methods' (Worth 1977, 70). While the first three are conceivable and were emulated in method, the fourth part has yet to be developed, at least in the world of visual anthropology.

Worth's domain of analysis was the symbolic visual environment or, to use his terminology indicative of the burgeoning VHS era at the time, 'our vidistic universe' 
(Worth 1977, 70). This universe included multiple examples of popular culture, the world of high art and visual elements that made up the personal symbolic environments of individuals. Worth's proposed study would encompass the analysis of the totality of one's visual culture. Thus, the 'ethnographic semiotic' study would describe the macro ethnographic account of a community, accompanied by participant observation in a number of different institutions that had a stake in defining the community, an applied component that focused on enabling individuals in the community to produce visual products through different mediums and, finally, an analysis of these generative products. These latter steps in the proposal closely paralleled Worth and Adair's Navajo Project and the ethnographic account Through Navajo eyes (Worth and Adair 1972). While Worth's overall project proposal is intriguing if not impossible, its lasting contribution and inspiration have been the drive to approach the way in which people engage and produce media in a qualitative ethnographic fashion.

Contemporary attempts to define an anthropology of media, media anthropology, media ethnography, ethnographic media or the larger project of theoretically and academically oriented visual anthropology owe their intellectual heritage and allegiance to the anthropology of visual communication and Sol Worth. For, as Larry Gross has stated, 'the central thread that runs through Sol Worth's research and writings is the question of how meaning is communicated through visual images' (Gross in Worth 1981, 1). Worth's almost 30-year-old book proposal foreshadows many of the questions and methods employed in current anthropological studies addressing media. The initial methodological components of the anthropology of visual communication focused on extending the analysis of visual communication to the actual social engagement between people and symbolic visual events. These visual events encompassed a variety of media that included film, television, print, art, dance, museum and architecture. Other terrains of media as defined by Dickey (1997), Spitulnik (1993) and Mahon (2000) include performance, the Internet and other modes of modern visual communication.

Portions of the media ethnography detailed below illustrate the practice of an ethnographic semiotics inspired by Worth through anthropological fieldwork conducted over a two-year period in Plano, Texas. At this time suburban individuals in Plano were in a state of moral panic over a phenomenon of teenage heroin overdose deaths in their community. However one defines community, this can be both limiting and extensive. The majority of these individuals were white, upper to middle class inhabitants of the suburb who identified themselves as residents of Plano, Texas. Many were directly caught up in the phenomenon owing to the death of a son or daughter. There were also a variety of stakeholders and their involvement as educators, police officers, politicians or medical doctors contributed directly to the generative media surrounding the moral panic. In addition, media creators were also studied to ascertain the generative capacities of different forms of media, including television, print and websites on a local and national level. Thus, all of these individuals represent a number of different discourses that combined during the event to create a new social subject known as the suburban teenage heroin addict. My particular interest was to examine how suburban 
residents of Plano interpreted a variety of media that depicted them and the experience they were undergoing, while also studying those individuals who created that media.

Through fieldwork and participant observation I examined how a teenage heroin overdose phenomenon was portrayed by a variety of media on both a national and a local level, and how suburban residents dealt with this coverage while attempting to create social policies and strategies to confront the force that was killing their teenagers and was considered to be 'invading' and 'targeting' the suburb from outside its safe confines. In order to do this, I adopted Worth's ethnographic semiotic approach to analyze a number of different media employing content analysis, elicitation and participant observation. Through these practices of media ethnography I am arguing that the events that occurred in Plano are emblematic of a moral panic and reflect a tortured symbolic and developmental history of the North American suburban environment that relies upon perceptions of racial homogeneity despite contemporary evidence that suggests otherwise.

\section{Media and the moral panic}

On Sunday, October 5, 1997 a full-page article entitled The Faces of heroin appeared in the Dallas Morning News, the predominant local newspaper serving Dallas, Texas and its surrounding suburbs. This article served as the flashpoint for a moral panic that occurred in the suburb of Plano, Texas over the following two years. This phenomenon was the subject of ethnographic fieldwork conducted during this time and since. On the full-page spread were pictures of nine, mostly white, male teenagers and one adult from the Dallas suburb with accompanying biographical data and descriptions of how they had died of heroin overdoses. The content of the single paragraph that served as the masthead of the article speaks to the developmental history of the North American suburban environment and a racial imagination that still governs perceptions of these social spaces.

\footnotetext{
For more than a decade, Plano recorded no heroin deaths. Then drug dealers, in search of a new market for a purer and highly addictive heroin, began moving into the suburbs. There, they found naïve young adults with money. Since 1996, at least 10 people with a Plano connection have died of heroin-related deaths. All but two were young white males. Their stories contradict the stereotype of heroin as a problem of the inner-city poor. Thousands of people are moving to Plano each year, enticed by its low crime rate, excellent schools and new housing developments. The attractions of the affluent suburban community of 200,000 gave some parents a false sense of security. Never would they have expected to find heroin here (Ball 1997).
}

The dichotomous and often antagonistic relationship in the United States and elsewhere between the city and the suburb that exists in both popular culture and academic research is nothing new. In the United States in particular, the city is often depicted as a dangerous ethnic space while the suburb is predominantly conceptualised as a safe, white cultural bastion. Different elements emerge from a content analysis of the preceding paragraph that reinforce this legacy and plot a roadmap for ethnographic media analysis. Both Plano and the teenagers who initially died of heroin overdoses are immediately established as innocent victims of forces from outside of the safe confines of the suburb. 
Plano, Texas is also described as an idyllic suburban space predominantly made up of white males with good schools and other trappings of American success attractive to potential residents. And, perhaps most importantly, the shock that something like a teenager heroin overdose problem could even exist in a suburb like Plano is revealed. It is perhaps the shock that resounds in the phrase heard continuously throughout fieldwork, 'How could this happen here?', that speaks most poignantly to the symbolic and developmental history of the North American suburb. This questions establishes the notion that any social problem like teenage heroin overdoses is antithetical to the suburban environment, but perhaps belongs somewhere outside of this social space.

During fieldwork over a period of more two years beginning in the autumn of 1997 I attempted to understand who produced the media products that dealt with the heroin phenomenon in Plano, to study the actual content of these media products, and to analyze the consumption and utilisation of messages within this media by individuals in the suburb. Of perhaps more importance was contextual ethnographic fieldwork conducted among a number of individuals and within several institutional settings in and around Plano to ascertain processes of suburban identity formation, perceptions of race and many other issues that conveyed an understanding of being a suburban resident in the United States. This ethnographic study was linked to the idea of describing the phenomenon occurring in Plano as a moral panic.

The notion of the moral panic originated in Britain in the early 1970s when sociologist Jock Young coined the term to discuss rising drug abuse among teenagers (Young 1971). Shortly thereafter, the publication of Stanley Cohen's Folk devils and moral panics: The creation of the mods and rockers, established a new direction in the analysis of youth subcultures and moral panics (Cohen 1972). Cohen sought to place teenagers and their supposed deviant activities within a larger cultural context that included how the general public perceived youth subcultures based on media representations, the consequent actions of a control culture influenced by these media representations, and the creation of a variety of social policies in response. Cohen noted how the conflation of all of these phenomena led to the idea that the supposed transgressions of British youth were more than socially problematic; they were evidence of a moral decline, worthy of a similarly moral reproach.

The moral panic concept has been utilised by researchers in several analytical fields and has focused on a variety of subjects since Cohen's original study. The most comprehensive media analysis that has used the concept of moral panics is Policing the crisis (Hall, Critcher, Jefferson, Clarke and Robert 1978). This study from the Contemporary Centre for Cultural Studies in Birmingham, England, looked at depictions of mugging in England to demonstrate how a moral panic dependent on ideas of race developed through media depictions of deviance and was related to other structural tendencies of the state to police individuals. In this study, Stuart Hall and others developed the theoretical tools of the 'signification spiral' and 'discourse convergence' to explain what occurs when social actors come together and enact a moral panic. By infusing ethnography with moral panic analysis, I demonstrate not only how the concept can 
have utility within anthropology, but also show how ethnographic detail can ground ideas extrapolated from media analysis. ${ }^{1}$ In particular, I demonstrate the utility of the moral panic concept alongside continuing efforts to study media within anthropology that demonstrate how media analysis is enriched with ethnographic detail.

One of the major criticisms of the moral panic model is the labeling of certain events as moral panics although they may be momentary concerns or long lasting conditions. One way to interrupt this trend is to infuse the moral panic model with ethnographic methodology, not only to ground media analysis and to determine the impact of media on the everyday lives of individuals in a succinct temporal fashion, but also to determine the validity of asking whether a certain phenomenon should be described as a moral panic. The stages in the development of a moral panic can be ascertained from a reading of Cohen's original analysis as provided by Thompson (1998):

1) Something or someone is defined as a threat to values or interests.

2) This threat is depicted in an easily recognisable form by the media.

3) There is a rapid build-up of public concern.

4) There is a response from authorities or opinion-makers.

5) The panic recedes or results in social change.

A new social subject was created during the moral panic in Plano identified as the suburban teenage heroin addict. While many teenagers tend to identify with any cultural image that contradicts their suburban environment, this was something more than listening to hip-hop music and wearing baggy clothing. This new subject was defined as a threat to the values and interests of the suburb (Stage 1). Alongside this subject was a pantheon of racialised invading forces that assisted in the creation of the suburban teenage heroin addict by targeting them and the space in which they lived. These newly defined threats were seized upon by the media in a sensationalist fashion and presented in an easily recognisable form (Stage 2) that was accompanied by an outpouring of public concern (Stage 3), culminating in a series of meetings and events and the eventual implementation of biased social policy (Stage 4). Eventually, the moral panic in Plano subsided when it was believed that the heroin problem was over when a number of teenagers were prosecuted alongside several Mexican nationals for drug trafficking and murder (Stage 5). This is despite the fact that heroin continued to have a presence among the pantheon of other drugs available to teenagers and there were subsequent deaths after the so-called end of the crisis.

In order to map out a contemporary moral panic over teenage heroin overdose deaths through ethnographic methodology, I conducted interviews and participant observation with police officers, parents, teenagers, drug counselors, doctors, politicians and a number of other individuals in and around the suburb of Plano. During fieldwork several things began to appear. In addition to representing individual responses to the crisis that was occurring, each of the individuals I spoke to was 'toeing a party line' or representing an institution such as politics, law enforcement or the medical community 
and fighting for the stake each institution had in the phenomenon. The police wanted to look tough and proactive. The medical community wanted to appear as though they were on top of the situation. Politicians wanted to demonstrate how they were acting in the benefit of the community.

Blame for the heroin crisis in Plano was being directed toward external racial and national sources, from Mexican nationals to the North American Free Trade Agreement, often referred to as the North American Free Trafficking Agreement within Plano, and mysterious inner-city drug dealers (coded as Black) who were 'jumping the tracks' to the suburb both in media depictions and in the conversations and policy initiatives of individuals representing the control culture in the suburb. All of these events were occurring prior to the $\mathrm{Y} 2 \mathrm{~K}$ conversion deadline, so fluid discussions at various community meetings about putting walls up around the suburb easily included the rationalisation to keep out both heroin dealers and looters from the 'bad part of town' who would invade at midnight on December 31, 1999 when all computers went down. Each element of the moral panic occurring disrupted the predominant media image, marketing and branding of Plano as pristine, safe from crime and an ideal place to raise children and teenagers. And, when the link between dead teenagers and property values is made, different perceptions of what it means to be a suburban resident appear.

\section{The suburban field site: Plano, Texas}

Perhaps the best way to introduce the suburb of Plano, Texas is to rely upon just one of the multitude of branding and marketing strategies meant to entice families and businesses to move there. The following introduction to the 1999 Chamber of Commerce brochure for Plano presents a picture of the suburban community reinforcing many of the descriptive elements found within the Faces of heroin article.

\section{Dear Newcomer,}

Thank you for your interest in Plano, Texas - one of the few U.S. cities to earn "All America City" status, the fifth-fastest growing city in our population category in the nation, the eighth safest city in the U.S. and the fourth most "Kid Friendly City" in the country! If these rankings aren't convincing enough, you will soon see that our community has even more to offer, whether you are looking for a place for your family to call home or a new location for your business to open its doors (Wentworth 1999).

Little more than a bedroom community in the middle of a cow pasture three decades ago, with a population of 20,000 in 1980 , Plano has become the fifth fastest growing city in the country and now boasts a population of 222030 and the designation of an 'All-America City' (City of Plano Website 2000). The population is split almost evenly between male and female, and the median age in the community is 34 years. Residents are predominantly white $(78 \%)$, while the Hispanic population makes up 10 percent of the community and five percent are African American. Sixty nine percent of homes are 
owned, while 31 percent are renter occupied (United States Census Data Website 2000). For all intents and purposes, Plano is considered a modern suburban success story. Its population and socioeconomic standing have steadily increased over the past 30 years, matching a national trend that has witnessed industry expand outside of American cities to outlying suburbs. Whereas up until the 1970s suburbs were functionally dependent on the central city and strengthened its economic base, many suburbs have now become independent financial, commercial and social centers (Jackson 1985). The journey to work no longer dictates a drive from the suburb to the city, as most commuters completely avoid downtown areas to work, shop, play and live. Conceptually, one can live in Dallas, but never actually be in Dallas. Thus, a different type of suburb has come into being that is only called a suburb because of its spatial relationship to the city.

Along with terms such as 'exurbia', 'technoburb', and 'superurbia', one term that has enjoyed popularity in defining the new modern American suburb is the 'edge city' (Garreau 1991). The modern edge city has five components that separate it from previous types of suburban development. The edge city must have at least five million square feet of office space, 600000 square feet of leasable retail space, which is basically the size of a large mall, more jobs than bedrooms (meaning that people must journey to the edge city for work), is perceived to be one place that includes many lifestyle components and was nothing like a city as recently as 30 years ago (Garreau 1991). Some of the elements of an edge city include tall buildings that resemble the skyscrapers of a downtown area or clustered business parks, bright lights, white-collar jobs, hotels, hospitals, corporate headquarters and a variety of popular restaurant and retail sites. Plano possesses all of the markers of the modern suburban edge city.

Although Plano is considered a successful suburb by any socioeconomic standard, it is also an unstable class environment. The technology market has enabled Plano to stay well below state and national unemployment trends, but the job market has suffered with the crash in Internet companies in the first few years of the new century. Many of the residents who live in Plano are corporate transplants who do not necessarily imagine themselves staying in Plano for more than a few years. They buy houses that they can sell quickly and without a problem. The reason that so many corporate transplants live in Plano is that it is considered a hospitable environment for corporations and a pleasant area in which to raise a family. Plano is home to the national headquarters for EDS, J.C. Penney, Frito Lay, Alcatel, Pagenet, Dr. Pepper/7up and Fina, among other corporations. These national headquarters are mostly housed in an area known as Legacy Row in the northern part of the suburb. Fifteen years ago Legacy Row was a two-lane country road, but now it is an eight-lane thoroughfare. The median family income is $\$ 61796$, the two high schools have consistently been in the top national rankings for a number of years, and the suburb has one of the highest concentrations of gated affluent developments in the country (City of Plano Website 2000). 


\section{An ethnographic semiotics}

One example of print media, the Faces of heroin article, served to galvanise community action and instigated the moral panic in Plano, Texas. A content analysis of this media established research questions that informed ethnographic method to investigate the generative and receptive elements of this media event. The Faces of heroin article also instigated discussion and debate during interviews and participant observation, becoming an excellent methodological device. In this sense, ethnographic research into a media event was driven by the actual media itself. The article also became an indispensable research tool for elicitation and analysis. By October 5, 1997 when the Faces of heroin article appeared in the Dallas Morning News and served as the flashpoint for the moral panic in Plano, 13 people had died of heroin overdoses in the immediate surrounding area since the beginning of 1996. Eleven of those were from Plano and nine were under the age of 21 . By the time the heroin problem had supposedly been solved, the number of dead teenagers by heroin overdose in Plano would total 18 , although this number is contested by various sources.

Whereas Plano had been represented in various media by signs of progress and industry up to coverage of the heroin overdose deaths, a new iconography of drugs and troubled teens made Plano a touchstone for any discussion of teenagers, suburbs and heroin in the American media. This coverage was overwhelming during the crisis and has continued to appear on a regular basis since that time. Any media coverage of Plano and its problems in the media was first grounded in the apparent ironic contradiction of the affluence in the suburb, and the presence of a drug that is supposedly antithetical to that environment. Along with images of syringes, a variety of drugs and lost teenagers, images of gated communities and mansions interspersed with drug paraphernalia became the new icons of Plano.

In addition to the Faces of heroin article, these subsequent images from national media sources became a rich source for soliciting a number of responses from suburban inhabitants. One of the most productive spaces to witness this in action was at a variety of PTA meetings and other community action group events where different people came together to voice their opinions on what was occurring and attempted to formulate strategies to deal with the situation. These meetings provided a space where different discourses and perspectives on how to deal with the crisis would converge, sometimes in a cataclysmic fashion. What occurred at points of discourse convergence was an amplification of the problem. Parents would blame the schools, who would blame the police, who would then identify a 'serious lack of parental involvement at the home level', which would incite the parents even more. After the finger pointing at one another, strategies and different means of addressing the problem were put forward. These strategies were often based on misperceptions and preferred meanings that emerged from the media accounts individuals had obtained and were utilising as reference materials at these meetings. Thus, when strategies meant to solve the problem were put forward, they were often based on false information or sensationalised ste- 
reotypes and caricatures from media examples, fueled by individual political agendas. When individuals within these public settings put these agendas forth, the Faces of heroin article was often in their hands as a visual example. The proclamations followed the narrative of the article, namely that something had to be done about an invading problem that was disrupting suburban life where the problem was not supposed to oc-cur. Quite often, this entailed the expression 'those damn Mexicans'.

The publication of the Faces of heroin article had a direct correlation with the creation of town hall meetings, drug summits and the formation of community organisations that marked the initiation of the moral panic in Plano in 1997. In this sense, the article was responsible for direct community action, or at least was believed to be. As Linda Ball, the reporter who wrote the Faces of heroin article, stated:

I would like to think that the story did wake people up because a month later 5000 people (actually approx. 1800 ) jammed the Plano Centre and I feel like that was a direct result of the story (Interview 1999).

In addition, the Faces of heroin article defined the moral panic in Plano. It established a set of issues that would be used by individuals in Plano to discuss the phenomenon and formulate strategies on how to deal with it. Those details established the agendas for meetings and summits organised to respond to the presence of heroin in Plano. The article became the raison d'etre for new community groups created to deal with the problem. In addition, it seemed as if every single national news media outlet that came to Plano to report on the crisis read the article, even showing the image of the article as a photographic still in several exposés. The visual impact of the Faces of heroin article was what made its effect so profound. While the narrative of the newspaper report detailed different aspects of how heroin came to Plano and provided biographies of each individual who had died, it was the faces attached to those biographies that had such a profound effect on people. As one parent stated:

When I saw that article I couldn't believe it ... heroin in Plano? I'm sitting around on Sunday morning reading the paper and I see this? These kids looked just like my girls and their friends. I asked the girls about it and they said that it had been going on for a while and I was completely shocked. I cut it out and put it on the refrigerator as a constant reminder to all of us ... after that we started to talk to the girls about drugs and now I feel like we know more but you're never 100 percent sure... (Interview 1999).

While many felt that the article was beneficial, others thought it attempted to blow the problem out of proportion or to sensationalise the deaths of the teenagers. The presence of heroin in the suburb seemed to contradict any conventional understanding of the character of the suburb. It was as if people could not imagine that a drug like heroin could be present in Plano. This belief added to the impact of the article and was strategic in its publication:

Linda: From a journalist's standpoint it is news because it is new ... kids have been doing coke and drinking in the burbs forever, but the difference was that this was heroin and is new to the suburb and that the suburb was specifically targeted because the kids have a lot of disposable income and they were not exposed to it before, with no memory of it. 
MD: So the fact that it was new to the suburb made the story more appealing or sensational?

Linda: It was contradictory to the idea of the suburb and that was the idea for the story. It wasn't like these were sweet innocent kids that had never taken a drug before in their life, it was just a new drug to these kids that has been around for a long time and is usually associated with other people (Interview 1999).

A number of national news magazine shows came to Plano in the following months to report on the phenomenon, or they flew guests from Plano to their studios in New York and Los Angeles for interviews. Some of these shows and networks included Extra, Hard Copy, 20/20, Nightline, Good Morning America, The Today Show, CNN, 48 Hours, MTV, MSNBC and Dateline NBC. If these shows did not have an on-the-spot reporter standing in front of a graveyard, an affluent tract mansion or Plano Senior High School telling the story of suburban teenage tragedy, they had different members of the suburban control culture made up of parents, teachers, politicians, law enforcement officers or doctors as talking heads in boxes with the words 'son lost life to heroin' or 'overdose expert' underneath. The narratives of these reports emulated the Faces of heroin article by detailing the sensationalist problem, but also began a narrative trend of assigning blame for the problem outside of the suburban space.

\section{The moral panic resolved}

In the late spring of 1998, at the midpoint of the crisis with 14 teenagers dead from heroin overdoses, almost two dozen people were arrested at the two senior high schools in Plano in a drug sweep known as Operation Rockfest. Mentioned in the indictments of several Plano teenagers were seven Mexican nationals (a number that would eventually rise to 11) who were labeled as kingpins of the drug trafficking in Plano. The local and national media coverage of this event was intensive as images of parents in shock were transformed into images of Plano being tough - a ground zero for the American suburban drug war. In the next several months the majority of the teenagers brought under charges were able to plead down to probation or lesser sentences by giving information to prosecuting attorneys. Eventually, when the federal trial started in the spring of 1999, only 11 defendants of the original 29 that had been indicted were left to stand trial in a venue that had to be moved twice because of the publicity attached to the case. What is especially troubling about the 11 defendants that were left was that they were all Mexican nationals, while 18 co-defendants from Plano had now become federal witnesses against them.

Eventually, two of the 11 Mexican defendants were given life sentences under a rarely used federal enhancement statute reintroduced after a number of years specifically for this trial. Needless to say, there was an effort by parents to bring the death penalty as a possible sentence, but prosecutors were content with the inflation of sentences from an average of 20 years to life. The closest sentence for one of the Plano teenagers indicted was 48 months. While I do not argue with the necessity to punish drug dealers, the disparity between the Mexican nationals convicted and the Plano teenagers that 
assisted them was telling and speaks to the final stage in the evolution of the moral panic that occurred within the suburb. First, for many the heroin problem was solved when the sentences were handed out. The literal removal of brown bodies from the suburb became the crux for a belief that a heroin overdose problem was now solved. Throughout my fieldwork I had often heard various individuals use the phrases 'deport Mexicans' and 'get rid of drugs' in the same sentence. Media depictions reinforced this notion. The media barrage was halted after this moment, even though the heroin problem was still there. Essentially, the conclusion of the moral panic necessitated the end to media coverage even though another star football player from Plano would succumb to a heroin overdose only nine months later.

The disparity in sentencing also speaks to a suburban imagination that rests on a historical racial dichotomy between the supposedly white American suburb and the rest of society. In Plano, the same logic that determined where blame was laid for the presence of heroin within the suburb, namely on the inner city, Mexican Nationals and NAFTA, to protect the image of the suburb, now shaped the perception of social justice within the community. Essentially, a 'politics of substitution' had occurred, where critiques of NAFTA and racial bias revealed in the anxiety of individuals had been appeased through Operation Rockfest, the federal trial and the eventual sentenc-ing. By retaining an image of the suburb as clean of heroin, the suburb remained white. Thus, the perceived and historically supported belief in the 'whiteness' of the suburb is affirmed not only by where the blame for heroin was directed throughout the moral panic that enveloped Plano, but also in the perceived solution to the problem. Although the need to protect suburban life seemed to be the predominant melodrama portrayed in media coverage and in the responses of informants in Plano, the battle to preserve the 'idea' of the suburb and the 'ideal' suburban teenager was actually being waged. When problems that have plagued other social spaces occur in pristine communities like Plano, the question continues to be 'How could this happen here?' and the answer and blame for suburban anxiety consistently lie outside its safe and imagined confines.

\section{Conclusion}

The speed at which notions of race became entangled with other cultural ideas operating in the suburban community was almost as fast as the media coverage that initiated the moral panic in Plano. Subsequently, ideas about race began to compound a series of rationalisations about the heroin problem in Plano. Essentially, the presence of heroin was reduced to a racial argument when blame for the problem in Plano was placed on foreign sources that were given stereotypical identities. Ethnographic research led to the conclusion that the reason the moral panic over teenage heroin use in Plano was so intensive was because the phenomenon posed a threat to the very concept of suburban living itself that was embodied in the idealised teenagers of the perfect suburb. Thompson states, 'Implicit in the use of the two words moral panic is the suggestion that the threat is to something held sacred by or fundamental to the society ... a threat 
to the social order itself or an idealised conception of some part of it' (Thompson 1998, 8). The question I heard over and over again while conducting fieldwork was: 'How could this happen here?' This question not only set the stage for how blame was projected away from the suburb, but also showed that the very notion of heroin deaths were antithetical to the idea of suburbia in the first place. If white upper middle class teenagers could not be safe in one of the safest suburbs in America, even within a gated community within that safe suburb, then how could the suburb be said to exist at all? What made the suburb different from the supposedly dangerous urban environment these parents had avoided in the first place?

Once blame is placed on outside racial sources, one can show how 'devious' forces targeted the suburb and the innocent teenagers living there. This entire process exemplifies what Stuart Hall calls a 'politics of substitution' (Hall et al. 1978). Those who want to attack NAFTA, the inner city or other foreign spaces can couch this criticism in the language of protecting the suburb and its teenagers. The moral panic gains even more momentum when these forces from outside the suburban environment are given a racial identity that is seen as historically antithetical to the suburban environment itself. As this letter published in the local newspaper by one mother of a recovering addict, initially inspired by the Faces of heroin article and who evolved from an instant expert on heroin to a dedicated advocate of drug prevention and rehabilitation in Plano, attests:

In order to understand the new face of heroin, it is imperative that we understand the new face of the international drug cartel. It was no accident that this business found its way to Collin County. With a carefully designed marketing plan, they targeted our cities. They know our children, they know our life-styles, they know our weaknesses. The days of building secure, safe neighborhoods are over. The problems of the inner-city, which we have chosen to ignore, are now the problems of the suburbs (Nelson 1999) (Bold-type emphasis mine).

The key phrase in this statement, beside the constant references to a 'they' who live outside of the suburb, but nonetheless 'know' of the suburb, is the notion that the suburb was purposefully targeted. Overwhelmingly, in interviews and conversations with informants and community members, it was this notion that the suburb had been 'targeted' that was the most constant theme. By utilising this language, the suburb is positioned as a space where the potentiality for this problem was supposedly nonexistent. Thus, the suburb maintains its status as a 'clean' space that will reclaim its glory once the problem is eliminated. The process and belief systems that led to the perceived culmination of the moral panic in Plano rest upon a developmental and representational legacy of the American suburb that is dependent upon culturally ingrained ideas of race in North America. Just as ideas about race have been ingrained through various media that make of the visual world of suburban inhabitants, the ideas and perceptions of the American suburb have also been reinforced.

Through analysis inspired by the anthropology of visual communication and in particular Worth's idea of ethnographic semiotics, these notions were theorised and researched through fieldwork in Plano, Texas. The Faces of heroin article was only one 
piece of print media, but it was the beginning of a deluge that encompassed the suburb and its residents for the next two years and continues to affect the perceptions of the community. While all suburban residents are not automatons controlled by the media that they receive, individuals are embedded in media worlds that attempt to produce appealing media that sensationalises their suburban lives. When one reviews the type of media produced during the moral panic in Plano, it is easy to see how various media utilised the stereotypical notions of suburban residents for sensationalist news coverage of a teenage heroin overdose phenomenon. The media could have chosen to cover a number of other places in the United States where there were just as many if not more deaths from heroin overdoses, but Plano, because of its media history and trappings of contemporary socioeconomic success, appealed to the dichotomous sensibilities of media coverage and the ongoing dichotomous positioning of city and suburb/racialised and white that plague the United States.

\section{References}

Ball, L. 1997. The faces of heroin. Dallas Morning News, 30A. Dallas.

City of Plano. 2000. City of Plano Website. www.planotx.org (accessed July 18, 2005).

Cohen, S. 1972. Folk devils and moral panics: The creation of the mods and

rockers. London: MacGibbon and Kee.

Davidson, L. E., M.L. Rosenberg, J.A. Mercy, J. Franklin, J.T. Simmons. 1989. An

epidemiologic study of risk factors in two teenage suicide clusters. Journal of the American Medical Association 262 (19), 2687-2692.

Dickey, S. 1997. Anthropology and its contributions to studies of mass media.

International Social Science Journal 49 (3), 413-428.

Fordham, G. 2001. Moral panic and the construction of national order: HIV/Aids risk groups and moral boundaries in the creation of modern Thailand. Critique of Anthropology 21 (3), 259-316.

Garreau, J. 1991. Edge city: Life on the new frontier. New York: Anchor Books.

Hall, S., C. Critcher, T. Jefferson, J. Clarke and B. Robert. 1978. Policing the crisis: Mugging, the state and law and order. London: Macmillan.

Jackson, K. 1985. Crabgrass frontier: The suburbanization of the United States. New York: Oxford University Press.

Mahon, M. 2000. The visible evidence of cultural producers. Annual Review of Anthropology 29, 467-492.

Nelson, B. 1999. One mother's story. Plano Star Courier, 12. Plano.

Spitulnik, D. 1993.Anthropology and mass media. Annual Review of Anthropology 22, 293-315.

Thompson, K. 1998. Moral panics. London: Routledge.

Wentworth, P. 1999. Discover Plano 1999. Plano: Plano Chamber of Commerce. 
Worth, S. 1977. Guggenheim fellowship application. Studies in the Anthropology of Visual Communication 4 (2), 68-72.

Worth, S. 1981. Studying visual communication. Philadelphia: University of Pennsylvania Press.

Worth, S. and J. Adair. 1972. Through Navajo eyes: An exploration in film communication and anthropology. Bloomington: Indiana University Press.

Young, J.1971. The role of the police as amplifiers of deviance, negotiators of

drug control as seen in Notting Hill. In Images of deviance, ed. S. Cohen. Harmondsworth: Penguin.

\section{Endnotes}

1 Up to this point there has been only one article within anthropology that utilises the concept of moral panic, but this article tends to focus on the creation of stereotypes and larger processes of the state and other treatments of the particular subject, and does not include a media analysis (Fordham 2001). 